\title{
EXPERIENCIA DE LA RED NACIONAL DE ABASTECIMIENTO AGROALIMENTARIO EN COLOMBIA (PÓSTER)
}

\author{
Andrés Páez*, Kharen Pinilla y Liliana Mellizo
}

RENAAC, Colombia,Contacto@renaac.org

\section{Resumen}

A raíz de la pandemia asociada a la COVID19, en marzo del 2020 se creó la Red Nacional de Abastecimiento Agroalimentario en Colombia - RENAAC. El objetivo de la red fue apoyar los sistemas agroalimentarios locales, en particular, facilitar que la población campesina que no podía comercializar sus productos encontrara canales de intercambio y que la población urbana afectada por la crisis económica pudiera hallar alternativas para acceder al alimento, reduciendo su inseguridad alimentaria. La red se centró en el mapeo de actores, eventos y necesidades agroalimentarias. Para esto, se empleó una herramienta espacial en línea preexistente para la región central del país, que permite visualizar y enlazar a los diferentes actores del circuito agroalimentario, además de sucesos que afectan el abastecimiento. El mapeo se construye colectivamente, actualmente tienen 133 registros mapeados.

A partir del trabajo colaborativo, la RENAAC facilita la relación directa entre consumidores y productores, evitando la mayor cantidad de intermediarios innecesarios. Reconoce la importancia de tejer procesos urbanos y rurales como soporte básico de un sistema agroalimentario basado en los circuitos cortos de abastecimiento. Además, la RENAAC ha aportado diferentes espacios de discusión y análisis, tales como encuentros regionales y nacionales vía redes sociales, y espacios de coordinación con otras organizaciones, fomentando la divulgación y comunicación relevante para el sistema agroalimentario.

Palabras clave: Mapeo agroalimentario, Colombia, circuitos cortos, producción local, COVID19.

\section{Introducción}

Colombia posee distintas condiciones ecosistémicas que le otorgan un alto potencial agrícola, aunque la sostenibilidad agrícola se ha reducido en las últimas décadas. Hacia 1990, el sector agropecuario representaba el $22.3 \%$ del Producto Interno Bruto (PIB), pero esa contribución empezó a reducirse drásticamente con los efectos derivados de la apertura económica e integración a mercados agroalimentarios bajo políticas neoliberales. El aumento en importaciones de commodities alimenticias baratas sin proteger la producción nacional afectó de forma importante la producción doméstica de arroz y la Agricultura Campesina, Familiar y Comunitaria (ACFC). Entre tanto, la producción de productos con manejo agroindustrial como la palma de aceite y otros biocombustibles ha incrementado de forma acelerada en el país en reemplazo de las commodities alimentarias afectadas.

La reducción en la producción de alimentos se da en el marco de un alto conflicto por el uso y tenencia de la tierra. El 1\% de las fincas en latifundio tienen en su poder el $81 \%$ de la tierra productiva de Colombia, en las que predomina la ganadería en el $87 \%$ de los predios de más de 100 Ha. (OXFAM 2017). Actualmente sólo 5.2 millones de Ha. de 22 millones de Ha. aptas para la producción agrícola se emplean para tal fin. Sólo hay 15 millones de Ha. que deberían emplearse para la producción pecuaria, pero actualmente se emplean 34 millones, excedente resultante de una mala planificación territorial, la deforestación del país y el desplazamiento campesino generado por la alianza de los terratenientes con los grupos paramilitares. La transición a operaciones agrícolas de gran escala para producción agroindustrial y ganadera se ha especializado en agricultura de exportación y biocombustibles, pero no en la producción doméstica para garantizar el acceso al alimento de las y los colombianos.

Además de la inseguridad para acceder a factores productivos, el campesinado tiene diversas barreras para comercializar sus productos. Organizaciones como Greenpeace (2021) han identificado hasta tres intermediarios que no aportan ningún valor agregado en el proceso de distribución de alimentos y sí, un aumento en el precio para los consumidores finales; esta situación es crucial, pues la reducción del número de eslabones en las cadenas de distribución podría facilitar el acceso a los alimentos por parte de las personas con pocos ingresos, así como una mejoría en los recursos percibidos por parte de la población campesina por la venta de sus productos. 
La producción de papa ejemplifica los problemas en la producción y distribución de alimentos en Colombia; este tubérculo es parte importante de la gastronomía de varias regiones del territorio, y está incluido en la canasta básica del país. La papa (en este caso se habla de "papa gruesa") es pagada al productor por un precio de 80.000 COP (100 lb), llega a la plaza mayorista de Corabastos (Bogotá) por un valor de 90.000 COP y allí es revendida a un precio de 100.000 COP a los supermercados. El último intermediario, que es el supermercado, la revende al público a $1.300 \mathrm{COP}$ por libra, es decir $2.600 \mathrm{COP}$ por kilo, lo que multiplicado por el total de kilos por carga equivale a $130.000 \mathrm{COP}$, es decir un sobrecosto de 50.000 COP sobre el monto de la papa pagado al productor (Comunicación con agricultor del municipio de SaboyáBoyacá, 21 mayo 2021). Situación a la que habría de añadirse que la intermediación, además de aumentar los precios de los alimentos, también representa un aumento en la huella de carbono producida en el proceso de distribución de los mismos, con diferentes consecuencias para el ambiente y la salud humana.

Por otro lado, Colombia ya contaba con altas tasas de inseguridad alimentaria y nutricional antes de la emergencia sanitaria derivada de la COVID-19 (54,2 según la última encuesta de Nacional del Estado Nutricional; Ministerio de Salud y Protección Social, Instituto Colombiano de Bienestar Familiar, 2017). Para entender esa situación debe considerarse la concentración de la mayor parte de la población $(77,1 \%)$ en cabeceras municipales, especialmente alrededor de los grandes centros urbanos, así como la gran concentración y desigualdad en la tenencia de la tierra en el país (Guereña,2017), aspectos que hacen que para una gran proporción de hogares el acceso a los alimentos esté mediado por el factor monetario. No obstante, tal acceso es bastante limitado para una parte considerable de los habitantes del país, pues la pobreza monetaria en Colombia agrupa a un 42,5\% de los connacionales, y la pobreza monetaria extrema a un 15,2\%. (DANE,2021b) Por otra parte, en el campo colombiano, las condiciones de vida de sus habitantes denotan la acumulación histórica de varias fuentes de vulnerabilidad. Por ejemplo, actualmente el $91 \%$ de la población que habita centros poblados y rurales dispersos se encuentra en condición de pobreza monetaria o de vulnerabilidad, y el 34,5\% se encuentra en condición de pobreza multidimensional. Un factor importante tras la inseguridad alimentaria y monetaria en el campo es el limitado acceso a la tierra para las y los campesinos. Para redistribuir el acceso a los recursos productivos en una reivindicación con el campesinado, el Estado incluyó una reforma rural integral como punto uno de los acuerdos de paz firmados entre el Gobierno Nacional y la guerrilla de las FARC en 2016. Sin embargo, los acuerdos no se han cumplido según las metas y principios establecidos (Naranjo, Machica \& Valencia 2020; Vía Campesina,2020), por lo que objetivos como la puesta en marcha de un Sistema para la garantía progresiva del derecho a la alimentación (punto. 1.3.4), aún se ven bastante lejanos.

La ACFC ha resistido el contexto sociopolítico actual y es la que alimenta Colombia; este rol se ha hecho particularmente importante ante la crisis derivada de la COVID19 y la profundización de problemáticas frente al acceso a los alimentos que ya se presentaban en el país. Se estima que hacia 2016, el 83.5\% de los alimentos consumidos en Colombia fueron producidos por nuestros campesinos. Antes de las cuarentenas y medidas de aislamiento preventivo emitidas a causa de la aparición del virus, un promedio del $89,7 \%$ de los hogares a nivel nacional consumía 3 comidas al día; hoy esa cifra se ha reducido al 68,6\%, habiendo ciudades como por ejemplo Cartagena, donde solo un 33,4\% de la población tiene acceso a 3 comidas diarias (DANE, 2021a). Esto conversa con la experiencia del campesinado, pues según reportes de la FAO, tras una encuesta realizada a 1036 agricultor*s en abril del 2020, el 87\% de esta esta población reportó haberse visto afectada negativamente por la COVID19. Los impactos más comunes fueron el aumento de los precios de los agro insumos, especialmente en Córdoba, Boyacá y Tolima, y problemas de comercialización primaria en Antioquia y Putumayo. En el Chocó, Huila y Tolima, la ausencia de personas para trabajar fueron problemas frecuentes afectando la producción agrícola. En cuanto a sitios de comercialización y distribución de alimentos, en departamentos como Sucre, Guaviare, Casanare, Boyacá y Atlántico el aumento de precio de los alimentos tuvo un gran efecto sobre el acceso al alimento (FAO, 2020). Así, la crisis de la COVID-19 representa un llamado urgente para armonizar los procesos que medían la producción y el consumo de alimentos para la población colombiana.

\section{Objetivos}

La intención de la Red es fortalecer circuitos cortos de comercio, potencializar la creación de vínculos solidarios entre las distintas iniciativas de aprendizaje agroecológico y permacultura a escala nacional, intercambio de semillas nativas e insumos para la generación de huertas urbanas, fortalecer la medicina natural y ancestral a través del intercambio de alimentos y productos naturales; se busca incrementar las redes existentes en Bogotá y sus conexiones rurales de abastecimiento alimentario en diferentes partes del país, entre otros. 


\section{Metodología.}

Una Red Nacional de Mapeo Agroecológico facilita la generación de información espacial para potencializar las posibilidades de comunicación e interacción entre iniciativas agroecológicas, generando conexiones útiles que contrarresten los focos de poder que han sido perpetrados por sectores de la sociedad donde se concentra el poder económico agroindustrial, y que recreen lógicas territoriales de dominación. La plataforma interactiva garantiza la posibilidad de aportar información georreferenciada en tiempo real desde cualquier lugar del mundo, permitiendo generar procesos de creación cartográfica colaborativa de mapas comunitarios digitales y análogos.

El mayor interés del contra-mapeo es visibilizar los grupos que se ven afectados por diferentes conflictos territoriales y socio-ambientales, y que muchas veces se invisibilizan en los ejercicios de mapeo hegemónicos. Este tipo de mapeos colectivos y contra-hegemónicos se pueden denominar como "un proceso de creación que subvierte el lugar de enunciación para desafiar los relatos dominantes sobre los territorios". (Iconoclasistas, 2013, citado por, Hoinle, et al, 2018)

La Red Nacional de Abastecimiento Agroalimentario RENAAC incentiva la visibilidad de las iniciativas que puedan representar procesos alternativos y transformativos para el sistema alimentario de las diferentes ciudades y territorios del país. Este tipo de herramientas virtuales posibilitan el acceso libre y la participación directa de los agricultores urbanos en la construcción de saberes colectivos.

Gráfico 1. Página principal de la plataforma espacial en línea de la RENAAC.

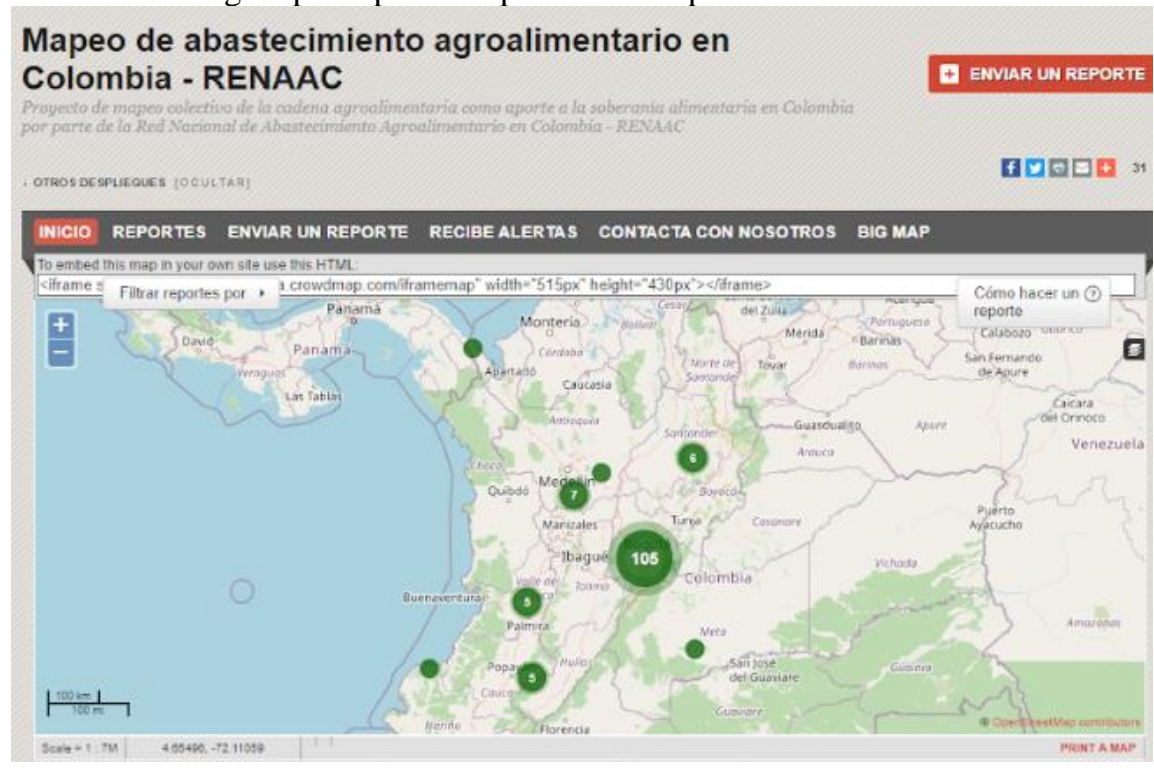

\section{Resultados}

Actualmente, el mapeo cuenta con 135 referencias de proyectos urbanos y rurales de agroecología, sobre todo en la región central del país. Sin embargo, aún falta georreferenciar muchas otras iniciativas para fortalecer el movimiento de agricultura urbana, principalmente aquellas experiencias con un enfoque agroecológico. Los registros están clasificados de la siguiente manera:

- 94 productores agropecuarios de los cuales 65 hacen parte de la Agricultura Campesina, Familiar y Comunitaria y 29 de la Agricultura Urbana.

- Se reportaron 37 experiencias con disponibilidad para intercambio de semillas e insumos distribuidas en Boyacá, Cundinamarca, Bogotá y Cauca.

- Se han reportado 2 registros de trueque o monedas alternativas para Bogotá y Popayán.

- Para mercados populares, se han registrado siete, en su mayoría en Cundinamarca, pero también (1) en Santander.

- En términos de servicios educativos agroecológicos, se reportaron 16 casos que abarcan Boyacá, Cundinamarca, Bogotá y Cauca. 
- En cuanto a Redes de Consumidores se han registrado 9 reportes en Bogotá, Boyacá, Tolima, Antioquia y Santander.

- En términos de puntos críticos (lugares de concentración popular ciudadana que se manifestaron, para exigir ayudas alimentarias al gobierno distrital y nacional, producto del confinamiento decretado en el mes de marzo del 2020), se reportaron 16 para Bogotá, tres en Medellín, y uno para Barranquilla como para Buenaventura.

Así mismo, se organizaron dos eventos de carácter nacional, el primero buscaba entender los retos a asumir por parte de la consolidación de una Red Nacional de Abastecimiento Agroalimentario con actores de carácter local, regional y nacional y el segundo, para reconocer las diferentes experiencias de redes de comercialización regional trabajadas por organizaciones campesinas en las diferentes partes del país. También se ha podido generar lazos de cooperación con otras organizaciones que trabajan en el abastecimiento agroalimentario, desde diferentes sectores sociales, tales como grupos académicos (Semillero de Investigación en Agroecología - HISHA de la Universidad Distrital de Bogotá), o redes locales de distribución (Mercado de los Pueblos).

\section{Conclusiones}

El trabajo colectivo urbano-rural permite que la población campesina y diversos sectores populares de la sociedad puedan acceder a tecnologías de comunicación, y puedan tejerse en múltiples redes de cooperación a través de un Sistema de Abastecimiento Agroalimentario consolida su integridad.

En el último año, han aumentado las plataformas web de iniciativas agroecológicas permitiendo al consumidor visualizar y comprar productos con solo conectarse a Internet desde cualquier dispositivo. Sin embargo, no hay una visión espacializada de las iniciativas presentes por departamento o municipio en Colombia, por lo que la RENAAC tiene como propósito servir como catálogo o plaza mayor digital que visibiliza en tiempo real la creación de conocimiento colectivo agroecológico, conectando personas o asociaciones que trabajan en territorios diversos con objetivos propios de mejora de la calidad de vida en poblador*s colombian*s.

\section{Bibliografía.}

DANE (marzo, 2021a) Encuesta Pulso Social, resultados novena ronda, recuperado del sitio web del departamento nacional de planeación: https://www.dane.gov.co/

DANE (abril, 2021b) POBREZA MONETARIA EN COLOMBIA, RESULTADOS 2020, recuperado del sitio web del departamento nacional de planeación: https://www.dane.gov.co/

FAO (2020) Coyuntura del Abastecimiento Alimentario en los Territorios rurales de Colombia. Disponible en:

https://nacionesunidas.org.co/Publicaciones-

FAO/Abastecimiento\%20COVID/Boletín\%20FAO\%20Situación\%20del\%20Abastecimiento\%20e n\%20zonas\%20rurales\%201.pdf

Guereña. A (2017) Radiografía de la desigualdad. Lo que nos dice el último censo agropecuario sobre la distribución de tierra en Colombia, informes y publicaciones, OXFAM, recuperado del sitio web de OXFAM International: https://www.oxfam.org/es/informes/radiografia-de-la-desigualdad

Greenpeace (2021) Manifiesto Nueva Cultura Alimentaria. Por un sistema Agroalimentario para Bogotá sostenible, resiliente e incluyente, recuperado del sitio web de Greenpeace: http://greenpeace.co/pdf/2021/Informe\%20Final_Sistema\%20Alimentario\%20de\%20Bogota_corr egido.pdf

Naranjo. S, Machica. D \& Valencia. M (2020) Cuadernos de la Implementación, número 6, La Reforma Rural Integral en Deuda, Centro de Pensamiento y Diálogo Político-CEPDIPO, recuperado de: https://cepdipo.org/portfolio/cuadernos-de-la-implementacion-6-la-reforma-rural-integral-endeuda/

Vía Campesina (2020) Colombia: Reforma rural integral - ¡Solo se ha completado el 4\%!, recuperado del sitio web de Via Campesina: https://viacampesina.org/es/colombia-reforma-rural-integral-solo-seha-completado-el-4 